\title{
La trascendencia socio-jurídica del cooperativismo agropecuario en Cuba
}

\author{
Daliani Mileni González Gutiérrez \\ Universidad de Cienfuegos, Cuba
}

doi: http://dx.doi.org/10.18543/dec-14-2019pp45-60

Recibido: 29-10-2019

Aceptado: 21-11-2019

Sumario: 1. Introducción. 2. Evolución del cooperativismo agropecuaria en Cuba. 2.1. Periodo Colonial. 2.2. Periodo Neocolonial. 2.3. Periodo Revolucionario. 3. Las novedades del Decreto-Ley No. 365/2018 y su Reglamento en el modelo cooperativo agrario cubano. 3.1. Concepto. 3.2. Constitución. 3.3. Los socios y las relaciones cooperativas. 3.4. Órganos sociales. 3.5. Régimen económico. 3.6. Organización Social. 3.7. Relaciones cooperativa-Estado. 4. Consideraciones finales.

Resumen: El movimiento cooperativo en Cuba, en los inicios se basaba en un fundamento mercantilista impulsado con el Código de Comercio, aunque encontró vestigios de su identidad en la Ley de Asociaciones de 1989. Durante la etapa neocolonial los impulsos del crecimiento de la cooperativa fueron mermados por la desidia y corrupción de sus gobernantes, por lo que en la etapa prerrevolucionaria la cooperativa no tuvo arraigo. Con el triunfo de la revolución se dictan varios cuerpos legales hasta la reciente promulgación del Decreto-Ley No. 365/2018 que analizados desde las variables concepto, constitución, socios y las relaciones cooperativas, órganos sociales, régimen económico, organización social y relaciones cooperativa-Estado, ofrece un paso de avance en la regulación jurídica y comprensión de la figura en el país.

Palabras clave: cooperativa agropecuaria, regulación jurídica.

Abstrac: The cooperative movement in Cuba, at the beginning it was based on a mercantilist foundation driven by the Commercial Code, although it found traces of its identity in the Associations Law of 1989. During the neocolonial stage the impulses of the growth of the cooperative were diminished by the negligence and corruption of its rulers, reason why in the prerevolutionary stage the cooperative did not have roots. With the triumph of the revolution several legal bodies are dictated until the recent promulgation of Decree-Law No. 365/2018 that it was analyzed from the variables concept, constitution, partners and cooperative relations, social organs, economic regime, social organization and cooperative relations-State, shows a step forward in the legal regulation and understanding of the figure in the country.

Keywords: agricultural cooperative, legal regulation. 


\section{Introducción}

El estudio de la evolución del tratamiento legal de las instituciones, permite constatar la visión del legislador, su compenetración con los imperativos del momento y la influencia ideológica y política que se quiere ejercer. Sistematizarla permite valorar la evolución de la correspondencia del marco normativo con el sociológico, para arribar a determinaciones científicas sobre la problemática jurídica tratada (Fernández Peiso, 2012: 27). Los estudios sobre el fenómeno cooperativo son cada vez más asiduos y con una marcada relevancia, en el marco de América Latina se han desarrollado importantes teorías relacionadas con el cooperativismo, como el acto jurídico cooperativo, y que constituyen un fuerte fundamento doctrinal para la materia, que se ha reflejado en los ordenamientos jurídicos nacionales.

Los antecedentes del cooperativismo pueden ser ubicados desde la comprensión por la humanidad de la ayuda mutua y solidaria para la consecución de sus objetivos, pero no encuentra una formalización hasta la Revolución Industrial donde los Pioneros de Rochdale deciden unirse para apalear las circunstancias de pobreza en la que se encontraba la clase trabajadora en la época; macando con este acto el nacimiento de un movimiento cooperativo sistematizado y la codificación de los principios del cooperativismo. Las bases teóricas de este proceso se ubican en la obra de Robert Owen y William King, además de Charles Fourier, en Francia y Raiffeisen en Alemania, los cuales sentaron las bases filosóficas de dicha institución.

El cooperativismo llegó a América del Norte durante los últimos años del siglo XIX y los primeros del XX. El periodista canadiense Alfonso Desjardins (1860-1937) trajo a su país la idea de las cooperativas de ahorro y crédito, fundando en 1900 una cooperativa de este mismo tipo en LivisQuébec y en 1906 logra que la legislación de Québec promulgue la primera ley de cooperativas de ahorro y crédito. Luego, en 1909, Alfonso Desjardins, logra fundar otra cooperativa de ahorro y crédito en Massachussets en los Estados Unidos, tal fundación y la labor de Eduardo A. Finile (1860-1937) y Roy F. Bergengren contribuyeron a que se desarrollara el cooperativismo en Estados Unidos y que sirviera como ejemplo al resto del continente americano.

«En América Latina surgieron las primeras experiencias cooperativas durante la mitad del siglo XIX, principalmente en Argentina, Brasil, México y Venezuela, y a partir de ahí, se fueron desarrollando en el siglo xx a lo largo de los distintos países de la región según diferentes influencias, como la Iglesia Católica, algunos gobiernos y los inmigrantes europeos.» (Corbalán, 2013) 
Durante la época de 1960 a 1970 principalmente se despliega en América Latina una iniciativa de reformas agrarias lo que favoreció el desarrollo del cooperativismo en la mayoría de países latinoamericanos.

«Las líneas básicas de esta normativa han sido consecuentemente determinadas por los comportamientos de quienes conforman a la cooperativa y por el movimiento socio económico cooperativo y su tránsito a través de los tiempos, afrontando cambiantes y contradictorias precisiones que sobre la actividad de la empresa cooperativa y ellos mismos, ejercen sus factores de poder, los mercados y las políticas públicas locales, regionales y también, globales.» (Schujman 2018: 21).

En Cuba, la práctica del cooperativismo como fenómeno económico y social es joven y alcanzó un progreso significativo después del triunfo de la Revolución. Antes de enero de 1959 la economía era agraria y esencialmente subdesarrollada. La industria se encargaba generalmente de los productos agrícolas o la industria extractiva para la exportación.

El cooperativismo en Cuba tuvo un despertar relativamente tardío a consecuencia de la dominación a la que estaba sometida la isla. En la época de la colonia no se manifestaron incidencias del fenómeno cooperativo. En el período pseudorrepublicano no existió desarrollo real, ni legal del cooperativismo, ni siquiera por medio de una legislación básica, por lo que se mantuvieron ubicado dentro de las genéricas asociaciones.

De acuerdo con McCormack Bequer y Sarría Cruz (2018: 75) «El movimiento cooperativo en Cuba en materia agraria, ha desempeñado un papel de extraordinaria importancia en el desarrollo económico y alimentario del país, no se concibe la producción de alimentos en Cuba sin tener en cuenta los altos resultados productivos aportados por este sector. El compromiso contraído por los campesinos cubanos desde el inicio del proceso revolucionario en compensación al apoyo brindado por el Estado está dado por los logros alcanzados por el movimiento cooperativo cubano.

El 24 de mayo del año 2019 se publica en la Gaceta Oficial de la República de Cuba Decreto-Ley No. 365/2018 «De las Cooperativas Agropecuarias» y Decreto No. 354/2018 Reglamento del Decreto-Ley De las Cooperativas Agropecuarias, ofreciendo un nuevo matiz normativo a las cooperativas agropecuarias en el país, por lo que resulta pertinente abordar los aspectos fundamentales de esta legislación respecto a las derogadas, con el objetivo de actualizar a los interesados en el tratamiento legislativo de la cooperativa agropecuaria en Cuba. 


\section{Evolución del cooperativismo en Cuba}

Son varios los autores (Fernández Peiso, 2012; Rodríguez Musa, 2018; McCormank Bequer, 2018) que han realizado sistematizaciones teóricas sobre la evolución del fenómeno cooperativo en Cuba y resulta coincidente marcar tres momentos de su desarrollo:

\subsection{Periodo Colonial}

El primero se circunscribe a la época colonial donde se importa los cuerpos legislativos de la colonia española, el Código de Comercio de 1885, que se hizo extensivo a Cuba en 1886, contiene en su artículo $124^{1}$ la posibilidad de crear cooperativas al amparo de sus normas siempre que cumplan con el requisito de ánimo de lucro, el Código Civil de $1889^{2}$ no constituía fundamento para la creación de las cooperativas, las omitió en tanto las cooperativas no calificaban por el contrato de sociedad, es mediante la Ley de Asociaciones de $1889^{3}$ que alcanzan un espacio legal, por lo que de acuerdo con Rodríguez Musa (2018: 75) «Sobre esta base es posible afirmar que la legislación colonial que rigió la cooperativa en la Cuba española fue reflejo de su tiempo, en tanto mostró el escepticismo y las incomprensiones del legislador acerca de un fenómeno cuya identidad jurídica aún no se perfilaba. Resultado de ello, no encontró la institución amparo legal apropiado para desarrollar su doble aspecto económico y social.»

1 Las compañías mutuas de seguro contra incendios, de combinaciones tontinas sobre la vida para auxilio a la vejez, y de cualquier otra clase, y las cooperativas de producción, de crédito o de consumo, solo se considerarán mercantiles y quedaran sujetas a las disposiciones de este Código cuando se dedicaren a actos de comercio extraños a la mutualidad o se convirtieran en sociedades a prima fija

2 El Código Civil fue hecho extensivo a Cuba por el Real Decreto de 31 de julio, declarándolo vigente a partir del 5 de noviembre, del propio año. El contrato de sociedad se define como (Código Civil, 1967) «La sociedad es un contrato por el cual dos o más personas se obligan a poner en común dinero, bienes o industrias, con ánimo de partir entre si las ganancias».

3 El Real Decreto de 13 de junio de 1889: Ley de Asociaciones, estableció: «El Derecho de Asociación que concede el Artículo 37 de la Constitución, podrá ejercerse libremente, conforme a lo que preceptúa esta Ley. En su consecuencia, quedan sometidas a las disposiciones de la misma las Asociación para fines religiosos, políticos, científicos, benéficos y de recreo o cualesquiera otros lícitos que no tengan por y exclusivo objeto el lucro o la ganancia.

Se regirán también por esta ley los gremios, Las sociedades de socorros mutuos, de previsión, de patronatos y las cooperativas de producción, crédito y consumo. 


\subsection{Período Neocolonial}

El segundo momento se asocia con la Cuba neocolonial, cuando se dictan cuerpos legales sobre cooperativas de diversa jerarquía (leyes, decretos leyes, decretos y resoluciones) de contenido administrativo, destinado a regular las ayudas económicas, su uso, disfrute y limitaciones; arrendamientos colectivos para la constitución de cooperativas para explotaciones agrícola y pecuarias; reglamentaciones laborales; normas de inscripción; creación de diferentes cooperativas, control e inspección.

El 8 de junio de 1940 se promulgó la Constitución de la República de Cuba que en su artículo 75 reconoció la formación de empresas cooperativas comerciales, agrícolas, industriales, de consumo u otras, disponiendo - como mandato sistematizador- que por ley se regulare su definición, constitución y funcionamiento, y las prescripciones para que no se violare el régimen de trabajo establecido constitucionalmente.

En las Disposiciones Transitorias en el Título Sexto en su sección primera se regula que las cooperativas habrían de ser fundadas por los Gobiernos Municipales en cada terminación municipal y que las mismas se beneficiarán con el reparto de tierras y casas, y adoptarían el nombre de José Martí. Tendrían estas cooperativas como fin, la adquisición de tierras laborables y construir casas baratas para campesinos, obreros, y empleados pobres siempre que estos no ostentaran la propiedad. Las mismas estarían fiscalizadas por el gobierno de la República de Cuba y la regirían y administrarías los cooperadores representados por un agente del municipio, uno de la provincia y un representante de las altas esferas del gobierno bajo la presidencia de este último, pero sin que el mismo pudiera decidir nada por sí solo.

Para la época en que se estaba viviendo, el solo reconocimiento del régimen cooperativo, fue un acierto de dicha Constitución, pero el régimen que fue propuesto estaba muy apartado de la esencia de una verdadera cooperativa ya que los principios que sirven de base al régimen cooperativo son muy distintos a lo que se enumeraron en la Carta Magna de 1940. A esto se la agrega el hecho de que había que pagar intereses por parte de los beneficiarios de las mismas y las cooperativas se caracterizan por la ausencia del ánimo de lucro.

En el alegato de defensa pronunciado por Fidel Castro, en el juicio del Moncada, se caracterizaba la situación rural y se consignaba como segunda ley de su programa, una Ley de Reforma Agraria que estableciera el principio de conceder la tierra a quienes la trabajaran; proponiendo un límite a la extensión de la propiedad agraria y adquirir el 
exceso con el doble objetivo de rescatar las tierras del Estado y distribuir el resto bajo el fomento de cooperativas (Pichardo, 1980: 549). El periodo posterior a esa fecha no dejó de estar condenado a la desidia y corrupción de los gobernantes, que impidieron el cumplimiento del mandato constitucional y el desarrollo cooperativo.

\subsection{Periodo Revolucionario}

El tercer periodo o etapa revolucionaria, puede ser estudiada en tres etapas:

- Primera: Nacen incipientes formas de cooperativas de trabajo (cañeras, ganaderas, pesqueras, carboneras, de maestros, entre otras) y cooperativas de servicio y consumo denominadas las Tiendas del Pueblo.

- Segunda: Esta etapa comienza al inicio de la década de los 60 por el surgimiento de un activo movimiento asociativo de campesinos privados, fundamentalmente los beneficiados de la Ley de Reforma Agraria. Se crean en esta época las Asociaciones Campesinas, las Organizaciones de Base de la Asociación Nacional de Agricultores Pequeños (en lo adelante ANAP) y las Cooperativas de Crédito y Servicios (en lo adelante CCS). En la década del 70 se hizo evidente la presencia de una clase campesina y se da comienzo a la formación de Cooperativas de Producción Agropecuaria (en lo adelante CPA) con el objetivo de unificar a los campesinos en formas colectivas de producción para aproximarlas a formas estatales de gestión. Estas dos formas de cooperativas adquieren presencia legal en la Constitución de 1976, encontrando su instrumentación en la Ley No. 36/1982, la cual fue derogada por la Ley No 95/2002. «Cooperativas de Producción Agropecuarias y de Créditos y Servicios».

- Tercera: La tercera etapa ocurre en los años 90 con la creación de las Unidades Básicas de Producción Cooperativa (en lo adelante UBPC), generadas a partir del fraccionamiento de la gran propiedad agrícola estatal, para esta forma de cooperativas se promulga el Decreto-Ley No 142/1993 «Sobre las Unidades Básicas de Producción Cooperativa» (Fernández Peiso, 2007: 319).

El 24 de mayo del año 2019 se publica en la Gaceta Oficial de la República de Cuba Decreto-Ley No. 365/2018 «De las Cooperativas Agropecuarias» y Decreto No. 354/2018 Reglamento del Decreto-Ley De las Cooperativas Agropecuarias, ofreciendo un nuevo matiz norma- 
tivo a las cooperativas agropecuarias en el país, por lo que resulta pertinente abordar los aspectos fundamentales de esta legislación respecto a las recientemente derogadas.

\section{Las novedades del Decreto-Ley No. 365/2018 y su Reglamento en el modelo cooperativo agrario cubano}

Las bases legales del surgimiento del movimiento cooperativo en Cuba, están determinadas en las Leyes de Reforma Agraria, las que sentaron los elementos iniciales de estas formas de producción (McCormack Bequer y Sarria Cruz, 2018: 67). El reconocimiento de esta figura está dado desde el texto constitucional hasta las normas específicas para su regulación, recientemente fueron derogados la Ley No 95/2002. "Cooperativas de Producción Agropecuarias y de Créditos y Servicios» y Decreto-Ley No. 142/1993 "Sobre las Unidades Básicas de Producción Cooperativa» por Decreto-Ley No. 365/2018 «De las Cooperativas Agropecuarias» y Decreto No. 354/2018 Reglamento del Decreto-Ley De las Cooperativas Agropecuarias, solo con la promulgación de esta nueva legislación constituye un paso de avance en la organización y uniformidad del ordenamiento jurídico cubano por lo que se analizará teniendo en cuenta las siguientes variables: concepto, constitución, los socios y las relaciones cooperativas, los órganos sociales, el régimen económico, la organización social y las relaciones cooperativaEstado 4 .

\subsection{Concepto}

Etimológicamente el término cooperativa, según la Real Academia de la Lengua Española, proviene del latín tardío cooperativus que significa: "Que coopera o puede cooperar a algo, sociedad cooperativa o establecimiento comercial en que se venden los artículos suministrados por una cooperativa» (Diccionario de la Lengua Española, 2017). Pero en la actualidad, la forma más usada de la palabra es para designar a los tipos de asociaciones, sociedades o empresas, que tengan como base los principios y valores cooperativos.

4 Las variables antes enunciadas constituyen las analizadas por Fernández Peiso en su tesis doctoral (2005) respecto a la Ley No. 95/2002 y Decreto-Ley No 142/1993, constituyendo esta obra referente teórico fundamental del presente trabajo. 
El concepto cooperativo debe puntualizar las posiciones que la dialéctica del desarrollo económico social y el reto que el futuro del país exige, consiste en ubicarla en su genuina dimensión para adaptarlo a las reales condiciones objetivas y propiciar su proyección hacia un futuro de prosperidad y expansión, teniendo en cuenta su influencia positiva en el entorno social y económico (Fernández Peiso, 2005: 111).

Antes de la promulgación del Decreto-Ley No. 365/2018 el marco legal de las cooperativas en el país carecía de la conceptualización unificada de la institución cooperativa, la definición se basaba en un grupo de características descriptivas de las cooperativas existentes ${ }^{5}$, de acuerdo con Fernández Peiso (2005: 176) las carencias conceptuales básicas presentes en la norma se resumen en tres niveles:

a) Como institución denominada cooperativa: no expresan los valores, contenidos, ni principios que la identifican; no las califican, ni desarrollan, como una forma específica de organizar la economía socialista mediante un modelo societario cooperativo, diferente al resto de los sujetos económicos que actúan en el país - estatales, mercantiles, individuales por cuenta propia- y no materializa el derecho asociativo enunciado en la Constitución y sus consecuencias.

b) Como modelo organizativo de administración: no se diferencia ni patrimonial, ni estructural, ni operativamente de los sujetos estatales; no declara, entre otras, las categorías empresa, capital social variable, no fines lucrativos y objeto social, que son fundamentos de la administración de un patrimonio social cooperativo.

c) Como sistematización legal: presenta un panorama normativo de contenido y terminología dispersa e inadecuada para regular una institución societaria de la misma naturaleza.

En contraste a tal realidad la nueva regulación cooperativa cubana parte de la conceptualización, en el artículo 2, apartado primero, de la cooperativa agropecuaria, poniendo de relieve que constituye una organización económica y social, señala que su objeto es la producción de bienes, la comercialización y la prestación de servicio, que se gestiona colectivamente y que tiene como finalidad la satisfacción de un interés privado (el de los cooperativistas) y social (el de las cooperativas). Tipifica las cooperativas agropecuarias que se constituirán al amparo de la presente legislación, manteniendo los tres tipos existentes

\footnotetext{
5 Artículo 2 Decreto-Ley No 142/1993 y artículos 4 y 5 Ley No. 95/2002.
} 
la UBPC, la CCS y la CPA, describe las características de las mismas, manteniendo la misma esencia técnica que en los cuerpos legales anteriores ${ }^{6}$.

\subsection{Constitución}

El acto de creación de la persona jurídica da a conocer los atributos necesarios y suficientes para su existencia, la puntualidad de reconocerle personalidad jurídica y la capacidad legal acompañante. Él forma parte del complejo diseño jurídico que para la gestión sea viable y es requerida de la seguridad jurídica suficiente, del acto normativo vinculante, que las dote del marco legal.

Respecto a la constitución no hay discusión alguna sobre el reconocimiento de la cooperativa como una persona jurídica, la que puede ser definida como: "la agrupación de personas individuales o patrimonios, con una estructura orgánica tal que les permita cumplir intereses económicos y sociales, así como jurídicos, reconocidos estos por la voluntad del Estado» (Valdés y Fernández, 2004: 147). Para Orrego, (2013: 2) «la persona jurídica tiene dos elementos esenciales: elemento material, esto es, un conjunto de personas o bienes con una finalidad común y elemento ideal, reconocimiento explícito por parte de la autoridad de su individualidad, de su capacidad de actuar en el mundo jurídico»

Según Valdés y Fernández (2004) las personas jurídicas deben cumplir con cuatro requisitos indispensables para que sea reconocida su existencia: Unidad orgánica, que consiste en la estructura que tomará la persona jurídica para actuar, que quedará establecida en sus estatutos de conformación. El siguiente elemento radica en poseer patrimonio propio diferente al patrimonio de las personas que la conforman con el cual se pueda responder ante las obligaciones que contraiga. Responsabilidad independiente es otro de los elementos, la cual se logra respondiendo de sus obligaciones con su patrimonio y, por último, el derecho de actuar jurídicamente a nombre propio, a pesar de contar con personas naturales que la represente, las actuaciones que realicen se constituirán en nombre de la persona jurídica como manifestación de su voluntad.

El nacimiento de la persona jurídica está dado, en primer lugar, por la formación del ente a partir de la voluntad de los interesados en su

6 Artículo 4 hasta el artículo 7 del Decreto-Ley No. 365/2018. 
creación, acompañado estrechamente del reconocimiento legal de su existencia a partir de la inscripción en el registro correspondiente, por lo que el nacimiento de esta persona jurídica no se configura hasta que no se inscribe y es en este acto donde adquiere su personalidad jurídica. Según el Capítulo II del Decreto-Ley No. 365/2018 son tres los elementos que se requieren para constituir a la cooperativa agropecuaria y que esta tenga personalidad jurídica para operar como sujeto económico.

El primero de ellos es la autorización del Ministro de la Agricultura, este elemento requiere de una cadena de autorizaciones, que comienzan con la manifestación volitiva de los futuros miembros de la cooperativa, transitando por la aprobación de los delegados o directores municipales y provinciales, que elaboran la solicitud y requiere, además, el visto bueno de la organización superior de dirección empresarial correspondiente, así como de la Asociación Nacional de Agricultores Pequeños o del sindicato concerniente. De acuerdo con Fernández (2005: 80) la constitución de las cooperativas está supeditada a voluntad ajena - autoridad competente- que dispone requisitos y ejecuta actos, para emitir su autorización constitutiva, que no hacen más que aceptarse por sus futuros integrantes.

El segundo de los requisitos es la formalización de la constitución de la cooperativa en Asamblea de Constitución. En este momento de la vida de la cooperativa, la misma se encuentra constituida a través de la Resolución del Ministro de la Agricultura conformándose bajo la fórmula de la autorización Administrativa y no constituye un requisito exigido legalmente la escritura pública, limitando la voluntad de los socios que la componen.

El último de los elementos es la inscripción en el Registro correspondiente para marcar el nacimiento de la personalidad jurídica. Tal factor constituye un avance de la regulación de la figura. En la legislación relativa a la materia, recientemente derogada, la inscripción de la institución constituía una formalidad administrativa dispuesta por la Ley, que se ejercía en la Oficina Nacional de Estadística y no constituía el punto de partida para el ejercicio de una personalidad jurídica efectiva, sino un registro meramente declarativo. En la nueva legislación la inscripción se practica ante el Registro Mercantil y es el acto que establece el surgimiento de la personalidad jurídica.

\subsection{Los socios y las relaciones cooperativas}

Al crearse la persona jurídica (dígase cooperativa) ocurre una separación de la personalidad de los socios y la institución. La nueva per- 
sona desarrolla relaciones jurídicas internas (con sus creadores y empleados) y externas (con terceros). A esos efectos es determinante identificar lo distintivo de las relaciones internas, pues ellas están en correspondencia con la posición que ocupa el individuo en la organización: ser socio o empleado; y dependen del acto jurídico que los vincule (Fernández, 2005: 119).

Al igual que en las legislaciones precedentes, relativas a la materia, el Decreto-Ley No. 365/2018 sigue un orden lógico para regular el elemento subjetivo que compone a la cooperativa agropecuaria. La denominación legal para la persona natural miembro de una cooperativa de este tipo es: cooperativista ${ }^{7}$ y se distinguen las personas que pueden conformar la cooperativas: para la UBPC, las personas naturales, para la CPA, en primer lugar los Agricultores Pequeños y en segundo lugar las personas naturales que concluyan satisfactoriamente el período de prueba y sean admitidos por la Asamblea General de la cooperativa y la CCS: agricultores pequeños, los familiares de los referidos agricultores que estén vinculados a la tierra, los apicultores y los trabajadores que concluyan satisfactoriamente el período de prueba y sean admitidos por la Asamblea General. Desde el punto de vista sustantivo toda persona con capacidad legal puede ser miembro.

Las aportaciones al capital social, tampoco presenta un tratamiento uniforme, tal situación está dada por las particularidades propias de cada cooperativa y se hereda de la legislación anterior «la exclusión del principio de responsabilidad material de los socios por la integración y utilización del patrimonio y en consecuencia de las deudas sociales» (Fernández, 2005: 87).

Respecto a la solución de conflictos es importante tener en cuenta que estos pueden surgir entre cooperativas con terceros sujetos, ya sean personas naturales o jurídicas y en este caso las reglas de competencia se aplicarán de acuerdo al litigio devenido. En el particular de los conflictos surgidos entre socio-socio y socio-cooperativa solo tienen sustanciación al interior de la cooperativa y culminan en la Asamblea General, diferencia fundamental con los trabajadores asalariados que pueden acudir a la vía judicial a dirimir sus conflictos. Erróneo fuera considerar la posibilidad de acudir a sede laboral para solucionar conflictos societarios, pero limitar la posibilidad de acudir ante los tribunales desfiguraría la institución y por ende son desechables las menciones de propietario social o colec-

7 Artículo 3. Se considera cooperativista, a los efectos del presente Decreto-Ley, a toda persona natural socia de una cooperativa agropecuaria. 
tivo, que como categoría se aplican para diferenciar al cooperativista del trabajador asalariado.

\section{4. Órganos sociales}

El elemento material de la persona jurídica, su estructura orgánica, es resultado de la necesidad de distribuir las funciones que va a desarrollar, pues al igual que la persona natural, tiene que poseer diversos órganos para lograr su cometido social. Ellos se vertebran distribuyendo racionalmente, la misión y competencia de cada uno, de manera tal que su composición garantice el funcionamiento del todo (Fernández, 2005: 122).

En calidad de órganos sociales se presenta la Asamblea General ${ }^{8}$, la Junta Directiva9 y la Comisión de Control y Fiscalización y como figura directiva el presidente y el económico. Si bien la nueva legislación delimita las funciones y responsabilidades de cada órgano todavía adolece de imprecisiones técnicas y mezcla terminológica que confunde y oscurece la esencia, el contenido y las funciones de cada órgano.

\subsection{Régimen económico}

A decir de Fajardo (2018: 167), la Ley regula como la cooperativa obtiene sus ingresos, como atiende sus gastos y que destino da a sus resultados teniendo en cuenta que en su actividad ordinaria tiene una participación directa sus miembros, por el trabajo prestado o los servicios recibidos. En tal sentido hay que atender al Capítulo VII y Capítulo VIII del Decreto-Ley No. 365/2018 denominados «Del patrimonio» y "Del régimen económico» respectivamente, donde se hacen vigentes particularidades similares a las legisladas en la normativa anterior, en las tres modalidades de cooperativas se crea un patrimonio propio diferente al de sus miembros (requisito indispensable para considerarla persona jurídica) incluso, para la CCS aunque la titularidad de tierras

8 La Asamblea General es el órgano superior de dirección de las cooperativas agropecuarias, se integra por todos los cooperativistas que eligen, mediante el voto directo y secreto, al presidente y demás miembros de la Junta Directiva por el término establecido en el Reglamento del presente Decreto-Ley.

9 La Junta Directiva es el órgano de dirección de la cooperativa agropecuaria y se subordina a la Asamblea General, a la cual rinde cuentas periódicamente de sus actos y decisiones; su integración se dispone en el Reglamento del presente Decreto-Ley. 
y bienes esté en el campesino, integra para sí un patrimonio propio e irrepartible.

Se mantiene la figura de los anticipos y la remuneración en función de la cantidad y calidad del trabajo prestado. La nueva normativa en la materia establece con el monto utilitario el pago de tributos, la reserva para contingencias, el fondo para desarrollo y acciones socioculturales y alguna otra deuda. El resto de las utilidades se distribuyen según corresponda.

\subsection{Organización Social}

La situación de las organizaciones sociales se mantiene similar. El cooperativismo cubano es representado por dos organizaciones sociales: la Asociación Nacional de Agricultores Pequeños y la Central de Trabajadores de Cuba, la primera encamina su misión social a la solución de los problemas sociales del campesinado y la segunda de los trabajadores. Ambas se insertan en el tejido cooperativo desde la creación y existencia de la cooperativa, legitimada por normas que se manifiestan desde el acompañamiento de la Administración en la promoción de la voluntad de los socios para crearla, como la función de controlar su funcionamiento y gestión productiva.

La existencia de estas formas sociales ha tenido resultados en dos direcciones; por un lado, ha sido una limitante económico-empresarial, al reducir la auto-organización no propiciando la proyección hacia la intercooperación y la creación de ramificaciones cooperativas. Es válido señalar la existencia de voluntades y el establecimiento en los principios del cooperativismo nacional la ayuda entre cooperativas y la evolución a estructuras superiores dentro del fenómeno cooperativo.

Del otro lado, en lo social, su existencia ha sido favorable por la representatividad ante los sujetos políticos y administrativo territoriales y nacionales para impulsar el desarrollo social rural. Sin embargo, es patente que el fomento de la auto-organización y de las relaciones de intercooperación, acercadas al contenido de la institución, daría mayor vitalidad a la actividad cooperativa.

\subsection{Relaciones cooperativa-Estado}

El Decreto-Ley No. 365/2018 establece las relaciones con el Estado cubano propiamente dicho y con las instituciones estatales que lo componen. En la primera es dable destacar las relaciones de dependencia 
fundadas en la subordinación de su creación, gestión y funcionamiento a dictado administrativo. Las relaciones con el sector estatal se resumen fundamentalmente en los siguientes aspectos: 1. Cumplir con las obligaciones impuestas por el Estado. 2. Someterse al poder del control estatal. 3. Beneficiarse de la entrega de la tierra en usufructo, asistencia técnica, otorgamiento de créditos, inversiones y políticas de desarrollo en general. 4. Promoción de actividades educativas, culturales y sociales para el territorio o localidad. 5. Contratación y venta a entidades estatales de la producción.

Desde el nacimiento de las cooperativas agropecuarias en la etapa revolucionaria las relaciones entre el Estado y la Cooperativa se observan en dos escenarios: la promoción y el fomento. La promoción está dirigida a facilitar las condiciones para su existencia, mediante el efectivo ejercicio del Derecho de Asociación. El fomento se encamina a otorgarle un tratamiento legal diferenciado (Fernández, 2012: 278) Resulta novedoso y totalmente evolutivo el artículo $24^{10}$ del Decreto-Ley No. 365/2018, el cual permite comercializar el excedente con personas naturales o jurídicas que muestren interés.

\section{Consideraciones finales}

El fenómeno cooperativo está presente desde los primeros momentos de la existencia del ser humano, pero su sistematización como institución societaria se inicia con la Revolución Industrial. Las cooperativas nacen en los principios mutualistas, democráticos, solidarios y de fines no lucrativos. En la Cuba pre revolucionaria, no existió un desarrollo ni legal, ni real de lo cooperativo, pues se regulaba en disposiciones jurídicas que desvirtuaban la institución, transitando al genérico jurídico asociaciones. Con el triunfo de la Revolución se materializan ejercicios cooperativos, pero estaban carentes de un sustento legal apropiado que no alcanza su expresión hasta el reconocimiento constitucional de 1976.

Del análisis realizado se puede concluir que el nuevo marco legal para la cooperativa agropecuaria en Cuba, a pesar de poseer limitaciones sobre: el proceso de constitución de la cooperativa a través de

10 Artículo 24. Una vez cumplidos los contratos para los destinos de interés estatal u otros diferentes que tributan al plan de la economía, o cuando estos productos corran riesgo de perderse, o sus excedentes no sean contratados, las cooperativas agropecuarias pueden comercializar las producciones agropecuarias y forestales a las personas naturales y jurídicas que se interesen. 
la autorización administrativa, las mezclas terminológicas e imprecisiones en la regulación de las aportaciones al capital social y las funciones de los órganos y representantes de la misma. La imposibilidad de acudir a la vía judicial para solucionar los conflictos socio-socio y socio-cooperativa y la ausencia de disposiciones normativas para la ramificación cooperativa; constituye un paso de avance en el tratamiento legal de la figura en el ordenamiento jurídico cubano.

El Decreto-Ley No. 365/2018 brinda variadas áreas de mejoras en la concepción de la cooperativa: la inscripción en el registro mercantil para obtener la personalidad jurídica, le concede uno de los atributos imprescindibles para considerarla como persona y poder ejercer sus funciones en la economía nacional. Ofrece las bondades del beneficio de las cooperativas de los planes de desarrollo e inversiones estatales, además disfruta de la posibilidad de vender el excedente, no contratado estatalmente, a personas naturales o jurídicas con interés en ello, consolidándose como mecanismo de impulso al desarrollo rural.

Es necesario forjar la dirección del cooperativismo a posibilitar una competencia leal; proteger a los consumidores y al medio ambiente; impedir el desarrollo del ánimo de lucro y la corrupción y preservar el ejercicio fiscalizador y del control estatal. Todo ello encaminado a otorgar no solo la certeza del desarrollo sostenido y sustentable sino su indispensable seguridad jurídica.

\section{Bibliografía}

1. Real Academia de la lengua Española: Diccionario, 23 Edición, 2017. Recuperado de http://dle.rae.es/?id=AigzAPz

2. FajaRdo García, G.: «Análisis de la regulación de las cooperativas cubanas en el sector agropecuario desde la perspectiva del derecho cooperativo español». El cooperativismo en Cuba. Situación actual propuesta para su regulación y fomento, CIRIEC, España, 2018.

3. Pichardo, H.: Documentos para la Historia de Cuba, T. IV (primera parte), Ed. Ciencias Sociales, La Habana, 1980.

4. CorbalÁn, J.: "Las Cooperativas en Asia y América Latina». Revista de Mediterráneo Económico 24, 2013. Recuperado de http://www. publicacionescajamar.es/pdf/publicaciones-periodicas/mediterraneoeconomico/24/24-613.pdf (2013).

5. Fernández Peiso, L.A.: La Cooperativa Bases para su legislación en Cuba, Ciencias Sociales, La Habana, 2012.

6. Fernández Peiso, L.A.: «El fenómeno cooperativo en Cuba», Temas de Derecho Agrario Cubano, Félix Varela, La Habana, 2007. 
7. Fernández Peiso, L.A.: Lecturas en pro del cooperativismo, ante las imprescindibles transformaciones económicas del socialismo cubano, Ed. Universo Sur, Cienfuegos, 2006.

8. Fernández Peiso, L.A.: El fenómeno cooperativo y el modelo jurídico nacional. Propuesta para la nueva base jurídica del cooperativismo en Cuba, Tesis en opción al grado científico de Doctor en Ciencias Jurídicas, La Habana, Cuba, 2005.

9. Fernández Peiso, L.A.: Estudios jurídicos del cooperativismo, en Anuario del Centro de Investigaciones Jurídicas, La Habana, 2003.

10. Schumman, M.S.: "Historia del Derecho Cooperativo». Derecho Cooperativo Latinoamericano, Juruá, Brasil, 2018.

11. McCormackbequer, M. y SARRIA CRUz, S.: «Las cooperativas agrarias en Cuba». El cooperativismo en Cuba. Situación actual propuesta para su regulación y fomento, CIRIEC, España, 2018.

12. Navas, D.: Aporte de las cooperativas a un proceso de desarrollo con equidad en América Latina. Centro Internacional de formación de la OIT, Colombia, 1995.

13. Rodríguez Musa, O.: La constitucionalización de la cooperativa. Una propuesta para su redimensionamiento en Cuba, Virence, Brasil, 2017.

14. Rodríguez Musa, O.: "Historia y realidad jurídica de la cooperativa en Cuba», Derecho Cooperativo Latinoamericano, Juruá, Brasil, 2018.

15. OrRego AcuñA, J.A.: Las personas jurídicas, Chile, 2013. Recuperado de http://www.msal.gob.ar/persona jurídica/chile663/

16. RAMíreZ, J.: «El sector cooperativo de la agricultura cubana», Revista Cuba Socialista, junio de 1984.

17. Valdés Díaz, C.C. y Fernández Martínez, M.: «Elemento subjetivo de la relación jurídica civil. Persona natural y persona jurídica», Compendio de Derecho Civil (Primera), Ed. Félix Varela, La Habana, 2004.

\section{Legislación}

1. Asamblea nacional del Poder Popular, Cooperativas de Producción Agropecuarias y de Créditos y Servicios, Ley No. 95, La Habana, Cuba, 2002.

2. Asamblea Nacional del Poder Popular, Constitución de la República de Cuba, La Habana, Cuba, 2019.

3. Código de COMERCIO, Real Decreto No. 28, 1886.

4. Consejo de Estado sobre las Unidades Básicas de Producción Cooperativa, Decreto-Ley No. 142, 1993.

5. Consejo de Estado de las Cooperativas Agropecuarias, Decreto-Ley No. 365, 2018.

6. Consejo de Ministros, Reglamento del Decreto-Ley De las Cooperativas Agropecuarias Decreto, No. 354, 2018. 


\section{Derechos de autor}

http://dec.revistas.deusto.es/

La revista Deusto Estudios Cooperativos es una revista de acceso abierto lo que significa que es de libre acceso en su integridad inmediatamente después de la publicación de cada número. Se permite su lectura, la búsqueda, descarga, distribución y reutilización legal en cualquier tipo de soporte sólo para fines no comerciales y según lo previsto por la ley; sin la previa autorización de la Editorial (Universidad de Deusto) o el autor, siempre que la obra original sea debidamente citada (número, año, páginas y DOI si procede) y cualquier cambio en el original esté claramente indicado.

\section{Copyright}

The Deusto Journal of Cooperative Studies is an Open Access journal which means that it is free for full and immediate access, reading, search, download, distribution, and lawful reuse in any medium only for non-commercial purposes, without prior permission from the Publisher or the author; provided the original work is properly cited and any changes to the original are clearly indicated. 